\title{
“Ligji i pashkruar” në këndvështrimin e studiueses Margaret Hasluck
}

\author{
Ardita Dylgjeri
}

Ligji i pashkruar i shqiptarëve ka qenë (dhe akoma është) një corpus iuris unik në formën dhe organizimin e vet, një burim tërheqjeje i pafund për një numër të konsiderueshëm studiuesish shqiptarë dhe të huaj. Te grupimi i dytë i studiuesve mund të përmendet kontributi që kanë dhënë: Edith Durham, Margaret Hasluck, Rose Wilder Lane etj.

Disa pohojnë se bërthama e tij është po aq e vjetër sa Homeri, disa të tjerë e cilësojnë "mesjetar", por të gjithë bien dakord në një pikë: kur e cilësojnë atë si thelbin e jetës malësore, një anakronizëm të shkëlqyer, dhe (në këndvështrimin e të huajve), barbar ${ }^{1}$ në kapërcyellin e Europës moderne.

Sot ekzistojnë dy burime kryesore informacioni për ligjin e pashkruar të shqiptarëve, më specifikisht për Kanunin e Lekë Dukagjinit. Njëri është përshkrimi i ligjit të pandryshueshëm, të gjithëpushtetshëm dhe gjithëpërfshirës sipas studiueses Edith Durham në "High Albania/Shqipëria e Epërme"(1909). Tjetri është një tekst i Kanunit i bazuar në kërkimet e bëra nga një prift kosovar, Shtjefën Gjeçovi dhe i botuar nga Françeskanët në Shkodër në vitin $1953^{2}$.

Shkrimet e Edith Durham për Kanunin janë tërheqëse dhe shumë të lexuara. Ndryshe nga përshkrimet e Durham, teksti françeskan ishte menduar të shkruhej si një kod ligjor, sipas përcaktimit perëndimor të këtij termi. Ky

1 Young, A., Allcock, B. John. Black Lambs and Grey Falcons: Women Travellers in the Balkans, Berghan Books,Bradford, 2000, f.132

2 Gjeçov, SH, Kanuni i Lekë Dukagjinit, Gjonlekaj,1989. 
tekst gëzon një status të shenjtë në Shqipëri duke u cilësuar si përshkrim real, i gjallë i ligjit dhe njerëzve të maleve.

Që të dyja burimet janë të paçmuara, por njëkohësisht, ato kanë të metat e tyre. Studimi i Durham është tipik për etnografinë dhe zhvillimin e saj gjatë shekullit XIX. Kur europianët kuptuan që çdo fis kishte ligjet e veta, që "hipertrofia e ligjeve, më shumë sesa mungesa e ligjeve përbën bazën e jetës primitive $e^{3 "}$ ata ndryshuan brenda natës, nga një botë e egër pa ligje drejt një bote primitive, por "demokratike". Batalione me zyrtarë të lartë u shpërndanë nëpër fushat e Kaukazit, të Afrikës Lindore dhe viseve të tjera "periferike” për të mbledhur dhe kodifikuar ligjet e tyre zakonore. Pavarësisht pikëpamjes romantike që Durham mban përkundrejt këtij fenomeni, ajo do të shprehej se "Nuk ka popull tjetër në Europë, përvec shqiptarëve që të jetë kaq shumë nën tiraninë e ligjeve".

Françeskanët, nga ana tjetër kishin një axhendë të qartë politike dhe sociale. Ndërkohë që punonin me shënimet e Shtjefën Gjeçovit, ata synonin të forconin dhe unifikonin një komb të ri dhe githashtu, jo aksidentalisht, të mbështetnin kishën katolike në Shqipëri ${ }^{5}$. Françeskanët synonin të vendosnin një standard edhe aty ku kishte larmi, ata kërkonin të shfaqnin unitet edhe kur kishte diversitet. Qëllimi i tyre nuk ishte thjesht të dokumentonin ligjin shqiptar, por ta paraqitnin atë si një gur të themeleve të kulturës dhe traditës shqiptare, në kuadër të realitetit të ri shtet - formues dhe të shfaqnin rolin e tyre në ruajtjen dhe konsolidimin e trashëgimisë kulturore të kombit shqiptar.

Përveç dy studimeve të lartpërmendura, vlen të analizohet dhe vlerësohet kontributi i madh që Margaret Hasluck me veprën "Ligji $i$ pashkruar $i$ shqiptarëve”, i cili ashtu si shumë dorëshkrime të tjera të pafinalizuara, u botua pas vdekjes së saj në vitin 1954. Redaktimi i këtij studimi iu besua J. E. Anderson.

Margaret Hasluck cilësohet si etnografe, studiuese e përpiktë e folkorit, gjeografe, gjuhëtare, epigrafe, arkeologe, dijetare skoceze dhe etnologe e kulturës shqiptare. Ajo i kushtoi rreth 30 vjet të jetës së saj udhëtimeve në pjesën jugore të Ballkanit, fliste së paku tri gjuhë ballkanase, shtegtoi vazhdimisht dhe shkroi rreth këtyre eksperiencave. Ajo është e para studiuese

3 Malinowski, B. Crime and Customs in Savage Society, Routledge and Keagan Paul 1926, f. 9

4 Durham, E. High Albania, Virago, 1987, f.41

5 Young, A., Allcock, B. J.. Vep. e cit. f.132 


\section{Albanon}

Revistë kulturore

e Europës Perëndimore që ndërmori një punë sistematike e të përmbledhur etnografike në pjesën më të madhe të Shqipërisë dhe Maqedonisë.

Synimi kryesor i Margaret Hasluck ishte evidentimi i larmishmërisë, që shenjon thelbin e "Ligjit të Pashkruar". Ajo nuk shpërfaq thjesht ligjin, por kërkon të japë shumëllojshmërinë e variacioneve rajonale, përjashtimet e këtyre variacioneve si dhe mënyrën sesi këto njerëz jetojnë. "Ligji i Pashkruar" i Hasluck nuk është thjesht një set ligjesh dhe rregullash, por një mori vlerash dhe normash nënkulturore të cilat vërtiten rreth të njëjtit bosht, por me dallime të qarta mes tyre. "Ishte diversiteti ai që i pengonte qeveritë shqiptare të adptonin ligjet e pashkruara, jo primitiviteti apo etja për gjak" shprehet ajo. Për më tepër ajo theksonte se "Çdo formë e ligjit të pashkruar është ndryshuar, ka patur shtesa, riformuluar nga trupa ekspertësh të caktuar nga udhëheqësit."”

Megjithatë, romanticizmi i përshkrimit që ajo i bënte Kanunit, vjen atëherë kur vetë Hasluck detyrohej të pranonte se nderi mbeti një nga etalonet matëse të ligjit të pashkruar. Kështu, kur ajo nënvizonte këtë element, në shënimet gjatë udhëtimeve të saj në veri, vendos shenjën e barazimit mes "korisë dhe vdekjes" nga njëra anë, e "nderit dhe jetës" nga ana tjetër. Në lidhje më këtë, ajo do të shprehej: :“... Për disa burra toka është kapak alltëni”.

Pjesa më e madhe e studiuesve preferojnë ta shohin Kanunin të kufizuar vetëm në Malësinë e Veriut, por kjo nuk ndodh me Hasluck. Në realitet, ajo e konsideronon Kanunin si të gjithëpushtetshëm në të gjithë territorin shqiptar, ndërsa veçoritë e tij si forma të diversitetit nënkulturor shqiptar. Këtë lloj diversiteti ajo ia atribuon izolimit gjeografik dhe dukshëm masës së rezistencës së kulturës shqiptare nga ndikimet e huaja fetare apo ligjore të imponuara nga pushtuesit apo gjendja ekonomike.

Megjithatë, në këtë përshkrim të Kanunit prej Hasluck gjejmë dhe ndonjë rast, i cili në vetvete është ose përjashtim, ose keqkuptim i Kanunit. Mund të përmend këtu rastin e së drejtës së nipave për të marrë gjak në rajone të jugut të Shqipërisë9. Një konceptim i tillë duhet të ketë qenë një devijancë nga parimi i përgjithshëm. Nëse do të flasim për të drejta zakonore në Mirditë apo zona të tjera të Shqipërisë, në përgjithësi funksionon parimi "nipi asht pushk e varun”. Ky koncept përcakton se nipi nuk mund të kërkojë gjak pasi ai nuk e ka "pushkën në krah". Për më tepër, djali i motrës nuk i përket

6 Hasluck, M. The unwritten law, Cambridge, 1954, f.12

7 Po aty, fq. 9

8 AQSH, fondi 766,dosja 195, f. 14

9 Hasluck M., The unwritten law, vep. e cit,. f. 222 
lisit të gjakut, por atij të tamlit. Ai nuk ka tagër (detyrim) dhe as të drejta në derë të atit të së ëmës, përveç rasteve të dasmave ${ }^{10}$. Kanuni, me ndarjen e tij specifike dhe përcaktimin e të drejtave të fëmijëve dhe nipave, nuk detyron të tjerë persona përveç fisit apo bajrakut të marrin gjak. Në këto kushte bijtë e vajzave, si pjesëtarë të fisit të të atit, nuk mund dhe nuk duhej të përfshiheshin në marrjen e gjakut. Gjaku i përket shtëpisë në radhë të parë dhe vëllazërisë (vëllezër, kushërinj) dhe në raste të rralla katundit dhe bajrakut. Për pasojë dalja nga ky rregull do të shoqërohej me ndërhyrjen e pleqësisë dhe me lindjen e gjaqeve të reja. Në disa zona marrja e gjakut në këtë rrugë nuk mund të tolerohej dhe gjakësi mund të shkonte gjak - hup (gjakësi, pas vrasjes së tij, nuk linte pas të drejtën për t’ju marrë gjaku). Si përfundim, në thënien "nipi për dajon e shtie", Hasluck mund të ketë keqinterpretuar parimin kanunor. Nuk duhet të harrojmë se në procesionin e dasmës, zakoni e donte që në të dalë nga dera e dhëndrit dhe në të hyrë të fshatit të nuses të qiteshin batare armësh. Një e drejtë e tillë në zona të jugut mund të jetë e rezervuar dhe nipave dhe/ose në emër të nipave.

Hasluck sugjeron ndryshime radikale të ligjit në rrjedhën e kohës. Ajo përpiqet $t$ 'ia bashkangjisë këto ndryshimeve sociale në jetën e malësorëve gjatë asaj periudhe, sepse sipas saj është ligji i pashkruar ai që i adaptohet jetës dhe jo e anasjellta. ${ }^{11}$ Duke marrë në konsideratë ndryshimet radikale antropologjike të viteve `20, duhet theksuar ideja se nuk janë njerëzit ato që i nënshtrohen ligjeve, por ligjet ato që i përshtaten njerëzve ${ }^{12}$.

Hasluck ishte shumë skeptike nga natyra. Po aq sa i donte shqiptarët, aq edhe nuk i zinte besë lehtë. Kështu, siç ndiqte maqedonasit për të vërtetuar nëse ato agjëronin vërtet muajin e Ramazanit, ajo nuk besonte çdolloj informacioni që mund t $\mathrm{i}$ vinte nga informatorë shqiptarë. Libri i saj vazhdimisht kërkon të krahasojë ligjin në teori me atë në praktikë. Për më tepër krahasimet e saj nuk ishin të bazuara thjesht në informacione të dhëna nga persona të ndryshëm. Ndërsa qëndronte në Shalë, në fletoren e saj të shënimeve ajo krahason në vend mënyrën si vepronte dhe interpretohej Kanuni atje me të njëjtin fenomen në Dibër ${ }^{13}$.

Duke vepruar dhe menduar në këtë mënyrë, Hasluck kundërshton idenë e

10 Mustafa M. and Young A., Feud narratives: contemporary deployments of kanun in Shala Valley, northern Albania, fq.11; Për më tepër vetë Hasluck e ka të qartë një ndarje të tillë kur bën dallimin me "gjakut" dhe "tamlit", shiko: The unwritten law in Albania, f. 25

11 Hasluck M., The unwritten law, vep. e cit., f. 232

12 Malinowski, B., Crime and Customs in Savage Society, vep. e cit., f.125-127.

13 AQSH, fondi 766, dosja 13(195), f. 40 
mbështetur nga gjenerata e Durham, sipas së cilës, në shoqëritë fisnore klani është mbi gjithçka. Për malësorët e Hasluck, fisi është vërtet i rëndësishëm, por jo thelbi i jetës së tyre. Në të vërtetë, duke patur parasysh stilin "shkencor" me të cilin ky libër është shkruar, termi “individ” del në pah. Malësorët aty punojnë dhe luftojnë për prestigj dhe pushtet. Ata kanë synime më vete dhe janë në të njëjtën kohë hakmarrës për të drejtat e tyre. Ata nuk janë më skllevër të Kodit të Lekë Dukagjinit. Edhe pse malësorët shqiptarë nuk mund të thyejnë "zinxhirët e traditës së hershme", ata kërkojnë së paku t`i tendosin ato sa më shumë që të jetë e mundur. Edhe uniteti “lëvdues"-si diçka e nxitur dhe e mbështetur nga kisha katolike dhe më vonë edhe nga sistemi komunist, vihet në pikëpyetje në "Ligjin e pashkruar" të Hasluck. Në të vërtetë, ajo e kuptonte dhe e vlerësonte mitin e unitetit. Në fakt, ajo shkruan se "ndjenja e bashkimit ishte ushqyer nga çdo art $i$ mundshëm që njihej nga malësorët ${ }^{14 ”}$, por ajo asnjëherë nuk përpiqej të largohej shumë nga realiteti i rrëmujshëm.

Shkurt, Hasluck nuk përpiqet të thjeshtëzojë historinë. "Ligji i pashkruar" është çoroditës për variacionin e tij dhe i guximshëm për faktin që qëndron larg konkluzioneve artificiale. Në qoftë se teksti i Gjeçovit të lë shijen e një teksti të thatë dhe ai i Durham të duket i tejmbushur me ngjyra dhe heroizma, por jo i besueshëm; "Ligji i pashkruar" i Hasluck është çoroditës dhe i rrëmujshëm, malësorët aty shfaqen si mizorë dhe hakmarrës, si figura më tridimensionale, më njerëzore, më të besueshëm dhe padyshim më interesantë ${ }^{15}$.

Hasluck në një këndvështrim tjetër, kishte dy elemente, të cilat, nga njëra anë nxisnin dhe nga ana tjetër kushtëzonin vlerësimin e saj për Kanunin. Këto dy elemente ishin:

- Vlerësimi i fenomenit nga pikëpamja e një shkencëtari, dhe jo e një të apasionuari siç ishte Durham.

- Hasluck ishte e distancuar në hapësirë dhe në kohë nga fenomeni "Kanun".

Kanuni, edhe pse jo i kodifikuar në mënyrë të shkruar, ka uniformitet të paracaktuar dhe prezent në të gjithë format e shprehjes së tij. Në të gjithë krahinat shqiptare, Kanuni aplikohej dhe vinte theksin tek ata elemente të cilat ishin të parregulluara nga sisteme ligjore të mirëfillta ose atëherë kur shqiptarët refuzonin të pranonin zbatimin e një sistemi ligjor. Durham

14 Hasluck, M., The Unwritten law, vep. e cit., f 11

15 Hasluck M., Oral law in Albania, Vep. e cit., f 11 
vizitoi Shqipërinë, kur kjo e fundit ishte pjesë e Perandorisë Osmane dhe lëvizjet popullore po krijonin parakushtet e krijimit të shtetit shqiptar. Kushtetuta Osmane e xhonturqve në tërësinë e saj ishte e papranueshme për shqiptarët të cilët e shihnin si kërcënim për identitetin e tyre dhe interesat e tyre personale. Në këto kushte, ligji osman nuk pranohej në tërësi nga popullata shqiptare dhe zbatimi i saj ishte i pamundur. Popullata shqiptare, edhe më parë kishte shprehur rezistencën e saj ndaj sistemit ligjor osman duke e shpërfillur atë dhe duke pranuar zbatimin e legjislacionit osman atëherë dhe vetëm atëherë kur ky nuk dallonte nga Kanuni ose kur shprehej për fenomene që nuk përmendeshin në Kanun ${ }^{16}$. Hasluck erdhi dhe jetoi në Shqipëri kur shteti shqiptar ishte një realitet i prekshëm dhe, edhe pse në hapat e parë të jetës, kishte aftësinë që të mënjanonte dhe gradualisht të zëvendësonte rolin e Kanunit si rregullator i shoqërisë. Kanuni dhe zbatimi i tij, në kohën kur Hasluck jetoi në Shqipëri, nuk kishte të bënte më me rolin unifikues, me njësimin e popullsisë në një entitet nacional, që realizohej nga shteti tashmë, por me elemente praktike të jetës së përditshme. Për më tepër, Kanuni tashmë ishte dhe nën presionin e vazhdueshën të ligjit të mirëfilltë, i cili po gjente në suazën e monarkisë një pushtet të pamundur për t`u sfiduar. Hasluck i shihte Bajraktarët si kalorës deli ${ }^{17}$ duke ia atribuar këtë perceptim një gojëdhëne shqiptare, mirëpo, në rast se pranojmë këtë variant, termi "deli" do të lidhej ngushtë me kalorësit spahi, titullarë të timareve kufitare në rajonet ku ekzistonin bajrakët. Problemi është se kalorësit spahi ishin të gjithë myslimanë, ndërsa në Mirditë, Malësinë e Madhe, Krasniqen, Shpat, popullata ishte kryesisht e krishterë. Për më tepër, deri vonë këto zona ishin autonome dhe jo nën sundimin e sheriatit si të tilla jashtë zonës së timarit. Në thelb, bajraktarët nuk ishin tjetër veçse udhëheqës luftarakë të një krahine ${ }^{18}$. Në vazhdimin e studimit, Hasluck vëren se titulli bajraktar ishte i trashëgueshëm ose i fituar. Në të dyja rastet pushteti i bajraktarit ishte i kufizuar, pasi ishte pleqësia ose kuvendi ata që kufizonin pushtetin e tij. Si bajraktarët, të cilët Hasluck i njohu, ashtu edhe ata që kishte njohur më parë Durham, nuk ishin gjë tjetër, veçse krahu ekzekutiv i pushtetit në krahina.

16 Frashëri K., Identiteti kombëtar shqiptar dhe çështje të tjera (ndërhyrje në debatin Ismail Kadare - Rexhep Qose mbi identitetin evropian të shqiptarëve), EDISUD Spa.Tiranë, 2006, f. 60

17 Hasluck M, Kanuni, ligji i pashkruar i shqiptarëve, Bleu 1, Botime Lisitan, Tiranë, 2005, f. 126

18 Nicolay, Nicolas De, Dans I' empire de Soliman le Magnifique (red.Marrie - Christine Gomez - Géraud, Stéphane Yérasimos ) Paris 1989, f. 226 - 228 


\section{Albanon}

Revistë kulturore

Në rastin e Kanunit të Maleve bëhet fjalë për një individ i cili përfaqësonte krahinën, autonome nga të gjithë këndvështrimet, në marrëdhënie me pushtetin qeveritar osman. Po e njëjta gjë ndodhte edhe në Shpat, Martanesh, Malësi të Madhe dhe Krasniqen. Në rast se diku preferohej që të ishin individët më të aftë të përfaqësonin krahinën, diku tjetër preferohej vazhdimësia dhe besueshmëria te një familje.

Vitet `20 - 30 e kishin zbehur rolin e bajraktarëve të Kanunit. Ata tashmë ishin shndërruar në administratorë për llogari të qeverisë shqiptare dhe nxitonin të shfrytëzonin pushtetin e tyre në bajrakët e tyre për të zënë një post në ekzekutiv ose për t’ u zgjedhur në parlamentin shqiptar.

Nga ndryshimi kohor, jo në sasi vitesh, por në epoka historike të ndryshme, Kanuni nuk mund të kishte të njëjtin funksion dhe për pasojë është e natyrshme që atë, të cilën Durham e cilësoi si parakusht i unitetit fisnor (krahinor), Hasluck ta shihte si element individual ose që nxiste individualizmin.

Te Hasluck ka raste kur anashkalohen disa shprehje specifike në Kanun psh. Hasluck shprehet se zgjedhja e zotit të shtëpisë, apo e të parit të shtëpisë, jo detyrimisht rrjedh në mënyrë të drejtpërdrejtë nga rregulli i të parëlindurit. Ajo shprehet se ka raste, kur ky rregull nuk merret parasysh, por zgjidhet individi më i aftë për të drejtuar punët e familjes ${ }^{19}$. Ndërkohë që vetë Kanuni përveç të drejtës nga lindja, njihte edhe të drejtën e fituar:

\$. 20. Tagri, perlimi e detyra e të zot’t të shpis.

Mbas Kanunit, sundimi i shpis i perket ma të vjetrit nen kulm të shpis a se vllaut të parë; po s'paten ato veti , qi duhen per me krye ket zyre si e lyp detyra, atbotë zgidhet kuvendisht prej shpjakve njaj, qi të jet ma i meqem, i urtë e ma kujdestar. ${ }^{20}$

Në këtë paragraf, Kanuni parashikon mundësinë që të zgjidhet një individ i cili ka aftësitë dhe cilësitë për të drejtuar familjen. Duke qenë se këto aftësi dhe cilësi duhet të çonin në respektimin e Kanunit në çdo aspekt, barazia e anëtarëve të familjes duhet të ishte e padiskutueshme dhe e detyrueshme brenda rangjeve ku ata bënin pjesë.

Po kështu, Margaret Hasluck shprehet se në Martanesh kishte raste kur tejkaloheshin shpërblimet që caktonte Kanuni. Çështja shtrohet se kemi të bëjmë me dy lloje pagesash: ajo që ishte për gjykim kufijsh dhe një pagesë

19 Po aty, f. 46

20 Kanuni i i Lekë Dukagjinit, Krye i dytë, Ndërtimi i Familjes, Nye i Nandët, paragrafi 20 
për pleqnim pa specifikim. Pleqtë duhet të paguheshin 5 groshë paradite dhe dhjetë groshë për besë me gur. Problemi është se po Kanuni shprehej qartë se në gjykimin e kufijve duhej të merrej dëshmia dhe mendimi i të gjithëve, pavarësisht moshës dhe normalisht mund të zgjaste dhe periudha e gjykimit. Nga ana tjetër, në kohën e Lef Nosit, siç shprehet Hasluck, nuk duhet të harrojmë se vlera e parasë kishte ndryshuar tashmë ${ }^{21}$. Një tjetër problem i perceptimit të çështjes së perceptimit nga Hasluck, është kur thekson se në Lumë mallkimi ishte i dobët dhe bën shpjegimin se pretenduesi me pa të drejtë në këtë botë do të ketë ngatërresa, kurse në tjetrën mallkim² ${ }^{22}$. Ndërkaq, kufiri i pronës ishte po aq i shenjtë sa dhe varri:

\$.243. Eshtent e vorrit e guri i kufinit faqe Kanunit jânë paraz. Me lueit kufinin âsht nji si me lueit me eshtent e të dekunve. ${ }^{23}$

Në momentin kur "të ngucje varrin shkoje gjak - hup", nuk mund të kishte një fjalë më të rëndë se kjo. Kushdo që cënonte kufijtë kishte prekur një element tabu të shoqërisë shqiptare; kultin e të parëve dhe respektin për ta. Në këto kushte, individi që merrte përsipër të cënonte kufijtë, nëse gjendej në pretendim të padrejtë, jo vetëm humbte nderin dhe nuk përfillej më as në kuvend e as në pleqni, por mbarte mbi supe dhe rrezikun e ekzekutimit publik, mos më keq edhe përzënien e tij nga fshati apo dhe Flamuri (Bajraku), shtëpia i shembej dhe tokat i liheshin djerr. Nëse pleqnia shprehej në favor të një pretendenti, rrallë herë kishte kontestime. Natyrshëm, autoriteti i saj nuk vihej kurrë në diskutim. Një veprim i tillë mund të çonte deri në ndërhyrjen e Bajraktarit dhe pasojat ishin të paimagjinueshme. Në rastin e vrasjes në kuvend, në zonën e Lumës të përmendur nga Hasluck ${ }^{24}$, të gjitha gjasat janë të jetë një shembull i transmetuar ndër breza për t’u bërë shembull. Rrahja e përmendur po në të njëjtin paragraf përmbante dy rreziqe; pjesëmarrësit humbnin burrninë dhe më e keqja do të duhej ndërhyrja e fshatrave të Bajrakut për të sjellë në vete këtë rajon ku ishin tejkaluar të gjitha masat. Nga ana tjetër, krijoheshin premisat e gjaqeve, të cilat do të vazhdonin në pafundësi dhe sipas shumë gjasave, të vështira për t’u falur dhe me kosto të larta në jetë dhe ekonomi.

Veprime të tilla Kanuni i ndalonte dhe i dënonte dhe se kjo masë nuk njihej nga ai si ndëshkim. Kanuni shprehej qartë se çfarëdolloj mase ndëshkimi që

21 Hasluck M., Kanuni, ligji i pashkruar i shqiptarëve, Vep. e cit., f. 112

22 Po aty, f.108

23 Kanuni i i Lekë Dukagjinit, Krye i trembëdhetët, Kufini, Nye i Pesëdhetëeshtatë, paragrafi 243 


\section{Albanon}

Revistë kulturore

nuk parashtrohej në Kanun, ishte e ndaluar dhe kushdo që e aplikonte duhej të sillej urgjentisht në vijën e Kanunit.

Në përgjithësi, jo vetëm Margaret Hasluck, por edhe studiues të tjerë të huaj shprehin habi kur venë re që kapitulli i parë i Kanunit titullohet "Kisha". Ata vetë shprehin habi kur bëjnë krahasimin me realitetin fetar shqiptar ku islamizmi ishte dominant. Nëse kjo lidhej me të kaluarën e tyre të krishterë apo me një dëshirë të Françeskanëve për të treguar dominimin e tyre në jetën kulturore shqiptare apo për të demonstruar rolin e tyre në ruajtjen e trashëgimisë kulturore të kombit shqiptar. Në këndvështrimin tonë, ekzistenca e këtij fenomeni lidhet më shumë me konceptin e paprekshmërisë së klerit dhe objekteve të kultit, sesa me përkatësinë fetare. Nëse i kushtojmë kujdes, përshkrimi i kishës në Kanun paraqet detyrimet që ka famullia dhe kushdo tjetër ndaj kishës. Për më tepër, Kanuni zbatohej njëlloj si nga myslimanët ashtu dhe të krishterët, për këtë arsye çfarëdolloj përpjekje për ta "kristianizuar" atë duhet parë me rezervë dhe duhet cilësuar si e diskutueshme.

Edhe pse Kisha në vetvete është tregues i fesë së krishterë, në këtë rast ajo nuk i referohet objektit, por konceptit. Në Kanun, përcaktohet ndalimi i cënimit të çdo gjëje që lidhet me objektin e kultit, personelit, klerit apo gjithçka që është në pronësi dhe brenda kufirit të objektit të kultit. Ndoshta rrënjët e këtij kapitulli nuk duhen kërkuar në të shkuarën e krishterë të shqiptarëve, por në një të shkuar më të largët, pagane ${ }^{25}$. Autorët antikë na tregojnë që ilirët adhuronin fenomenet e natyrës. Ata i luteshin perëndive pagane dhe rrallë herë kishin faltore të ngritura, kryesisht ritualet kryheshin në natyrë dhe cënimi i çfarëdolloj gjëje brenda kufirit të këtij kompleksi në natyrë ishte tabu. Kontakti me kulturën greko - romake më pas bëri që besimi të institucionalizohet dhe të krijohen objekte të mirëfillta të kultit. Në këtë kënvështrim, përpos habisë së Hasluck, për emërtimin e kapitullit të parë, nuk ka ndonjë gjë të jashtëzakonshme. Edhe vetë Hasluck kishte vënë re se betimet më të rëndësishme të shqiptarëve lidheshin ose me elementë si Dielli, Toka apo dhe Shpirti i të parëve. Këto betime zëvendësonin betimin mbi ungjill apo për Zotin ose elementë të lidhur me të që hasen gjetiu. Zotat e shqiptarëve nuk pushuan së ekzistuari në ndërgjegjen e tyre edhe pas konvertimit në krishtërim së bashku me ligjet, kodin e nderit dhe legjendat e tyre.

25 Kordinjano F., Shqipëria. Përmes veprës dhe shkrimeve të misionarit të madh italian At Dominiko Pazi (1847 - 1914), Vëll. I, Botimet Almera, 2007, f. 117 
Një tjetër çështje që herë pas here shfaqet me forcë te "Ligji i pashkruar" është dhe roli i gruas në shoqërinë shqiptare. Gruaja ishte "shakull me mbajt" dhe nuk kishte të drejta në familjen shqiptare. Kur flet për rolin e grave në familje, Hasluck shprehet

“...por pasi martohen bashkëshortët e tyre ngurojnë që t’a përdorin (emrin e grave), ndërsa të tjerët $i$ dallojnë kur janë të sapomartuara si "e reja e Markut (e Asllanit ose e Vasilit), ndërsa më vonë, kur plaken si "gruaja" ose "plaka" e tij, kështu që emri i saj duke mos u përdorur, humbiste" 26 .

Në këtë kuadër, Hasluck nuk ka përmendur faktin se në disa zona të Elbasanit, femrave i drejtoheshin thjesht "oj ti e..." e shoqëruar me emrin e bashkëshortëve, ndërsa në Gash dhe Krasniqe i referoheshin si "gruja e..." ose "nuse e..." Nikajve, Berishëve etj., duke iu referuar fisit që i përkiste ose të parit të shtëpisë. Po të kemi parasysh se fisi dhe shtëpia ishin njësia bazë identifikuese e individëve, kjo nuk aplikohej vetëm me femrat, por edhe me fëmijët, djem apo vajza. Ajo që duhet të theksohet është se ka raste kur gratë bëjnë betime të tipit "pasha Zotin, pasha Palin, Zefin, pasha syun e ballit etj." ${ }^{27}$. Ato nuk mund të betoheshin për fëmijët e vet, sepse fëmijët nuk i përkisnin nënavë të tyre, as për prindërit e tyre pasi ato vetë nuk i përkisnin më prindërve të tyre, por mund të betoheshin për burrat e tyre pasi këta të fundit ishin e vetmja gjë që i jepte kuptim ekzistencës së tyre. Po te Kanuni, Hasluck tregon se gratë nuk kishin as të drejtën të qëndronin në të njëjtin mjedis me burrat, duke e cilësuar këtë si zakon të lidhur kryesisht me islamin. Një fenomen që vihej re te të gjthë shqiptarët, pavarësisht përkatësisë fetare, është mbyllja e grave ose shoqërimi i tyre me një mashkull të çfarëdo moshe ose me një grua më të vjetër. Por, Hasluck duke e cilësuar atë vetëm të lidhur me islamin, nuk përmend faktin se një fenomen i tillë hasej dhe në Mirditë apo në Rugovë zona këto katolike, për të mos folur për Shpatin. Edhe ky fenomen lidhet ngushtë me Kanunin, burrit nderi i merrej edhe kur atij i dhunohej gruaja ${ }^{28}$. Për të shmangur një gjë të tillë duhej që të merreshin të gjitha masat dhe kjo ishte detyrë e çdokujt që i thoshte vetes "burrë". Po kështu roli i gruas ishte inferior edhe në marrëdhëniet intime mes burrit dhe gruas. Hasluck kishte vënë re se bashkëshortja nuk mund t’i drejtohej të shoqit në publik. Në rast se ajo e bënte një gjë të tillë, atëherë opinioni për të

26 Hasluck. M.Ligji i pashkruar i shqiptarëve, Vep. e cit., f. 54

27 AQSH, fondi 766, dosja 13(195), f.73

28 Kanuni i Lekë Dukagjinit, kry i shtatëmbëdhetët, paragrafi 601, pika d 


\section{Albanon}

Revistë kulturore

shoqin do të ishte "ja ka djeg luga bujën"29. Një gjë e tillë ishte shumë më e theksuar kur gruaja këshillat ia jepte "faqe burrave", sepse, në fund të fundit, "ajo nuk kishte aq mend sa të këshillonte të shoqin".

Si përfundim, Hasluck, natyrshëm, do të shihte te Kanuni një mënyrë alternative në organizimin e jetës. Kanuni shpalosej para syve të saj, si studiuese, si një formë e pavarur e jetës komunitare në Shqipëri, një formë që tregonte ekzistencën e asaj ndërgjegjeje kombëtare, e cila ndoshta nëse do të duhej të ishte modifikuar dhe jo harruar, modifikuar dhe jo luftuar, duke qenë një pikë e fortë referimi në jetën e përditshme të shqiptarëve. Sot, shumë gjëra bëhen në emër të Kanunit apo të lidhura me të drejtën zakonore. Një shqyrtim i kujdesshëm, qoftë i veprës së Hasluck, qoftë i vetë Kanunit, na tregon se shumë gjëra në shoqërinë shqiptare ditët e sotme, nuk janë të justifikuara nga ligji i pashkruar shqiptar, por madje shpesh, bien ndesh me të.

\section{Bibliografia e përdorur}

Burime arkivore:

AQSH, fondi numër 32 Lef Nosi

AQSH, fondi numër 766 Margaret Hasluck

\section{Tekste:}

Durham, E. High Albania, Virago, 1987.

Frashëri K., Identiteti kombëtar shqiptar dhe çështje të tjera (ndërhyrje në debatin Ismail Kadare - Rexhep Qose mbi identitetin evropian të shqiptarëve), EDISUD Spa.Tiranë, 2006.

Gjeçov, SH, Kanuni i Lekë Dukagjinit, Gjonlekaj,1989.

Hasluck M, Kanuni, ligji i pashkruar i shqiptarëve, Bleu 1, Botime Lisitan, Tiranë, 2005..

Hasluck, M. The unwritten law, Cambridge, 1954.

Kordinjano F., Shqipëria. Përmes veprës dhe shkrimeve të misionarit të madh

29 Kjo shprehje në Krujë përdorej jo vetëm për të treguarse burri ishte bërë makut, por në shumë raste përdorej dhe se po dëgjonte gruan, detyra e së cilës ishte vetëm të shtronte bukë 
italian At Dominiko Pazi (1847 - 1914), Vëll. I, Botimet Almera, 2007.

Malinowski, B. Crime and Customs in Savage Society, Routledge and Keagan Paul, 1926.

Nicolay, Nicolas De, Dans l'empire de Soliman le Magnifique (red.Marrie Christine Gomez - Géraud, Stéphane Yérasimos ) Paris 1989.

Young, A., Allcock, B. John. Black Lambs and Grey Falcons: Women Travellers in the Balkans, Berghan Books,Bradford, 2000. 